\title{
The influence of individual factors on the number of reindeer (Cervidae) in the Baikal region
}

\author{
Yury Evgenjevich Vashukevich ${ }^{1, *}$, Pavel Ivanovich Zhovtyuk ${ }^{2}$, Svetlana Viktorovna Shvetsova ${ }^{1}$ and \\ Alexandr Sergeevich Bogdanov ${ }^{1}$ \\ ${ }^{1}$ Irkutsk State Academy of Agriculture, Irkutsk, Russia \\ ${ }^{2}$ Agency on Protection and Use of Fauna of Irkutsk Region, Irkutsk, Russia \\ *Correspondent: rector1@igsha.ru
}

\begin{abstract}
The article considers the influence of hunting (legitimate and uncontrolled) on the population of the Siberian roe deer, musk deer, elk, red and northern deer in Pribaikalje ${ }^{\dagger}$. The data on the forms and methods of hunting, the dynamics of the number of animals and the results of their production are given. For comparison, the acts of such a limiting factor as predators are specified. Reasons for the low number of wild ungulates are determined and main problems are formulated.
\end{abstract}

Keywords: hunting users, limits for hunting resources production, norms of allowable production, population dynamics, ratio of (predator-prey), reindeer (Cervidae), state hunting supervision, wild hoofed animals

(C) 2014 National Institute of Biological Resources

DOI: $10.12651 /$ JSR.2014.3.1.035

\section{INTRODUCTION}

Hunting for wild ungulates in Irkutsk region traditionally causes high interest in Siberian hunters and received products are of special value. The main objects of recreational hunting in the southern region are the Siberian roe deer, red deer (maral and Manchurian deer), elk, and to a lesser extent wild boar. In the northern regions mainly elk and reindeer are hunted for. Musk deer in majority is taken with traps for procurement of medicinal-technical raw materials - (musk gland). Commercial hunting is developed mainly for northern deer and elk. In areas of traditional residence, hunting is practiced in order to ensure maintenance of the existing lifestyle and implement traditional economic activities of indigenous peoples. Trophy hunting, including for foreign citizens, is rare and has no significant impact on the population. Most of ungulates are hunted for the meat and other derivatives such as horns, antlers, tails, musk, etc., which are of stable demand on the Asian market.

\section{Materials ANd Methods}

Study area is Irkutsk region, a subject of the Russian Federation which is located almost in the center of Asia, West of lake Baikal, between 51 and 65 Northern Parallels. The region area is $774846 \mathrm{~km}^{2}(4.53 \%$ of Russia's territory). Population density: 3.13 persons $/ \mathrm{km}^{2}$. The main forms of mega relief of the region are plateaus and mountains with the height ranging from 158 to 2999 meters above the sea level. The climate of the region is continental and sharp-continental, average annual temperatures are negative on the whole territory. The main part of the territory of the Irkutsk region (about 80\%) is occupied by boreal forests. Coniferous forests occupy over $90 \%$ of the forested area of Irkutsk region (Vinokurov and Sukhodolov, 1998).

Materials of the study were collected in the period from 2008 to 2013 We used data of departmental reporting on the protection and use of fauna of Irkutsk region and information given by experts. In the process of collecting the material we have analyzed the main publications on the topic. The main of them are the works of Smirnov (1978; 1989; 1990), Danilkin (2006), Melnikov and Melnikov (2008). Estimation of the number of hunting animals in their natural habitat was carried out by the authors and employees of profile government and commercial organizations on the basis of the guidelines on the implementation of state monitoring of the hunting resources and their habitats using the method of winter route accounting. Partially account of the objects of the animal world was held with the help of video recorders installed on places of seasonal concentration of animals according to the methodology of the training centre "Sibokhotnauka" of Irkutsk state academy of agriculture. Summary of results of the hunting resources was carried out according to the data provided by the hunting users in standard

\footnotetext{
${ }^{\dagger}$ Pribaikalje-Baikal area
} 
forms (Information about the production of wild ungulates and bear during hunting season). Annually, up to 130 reports on the production of hunting resources were analyzed. Information about the revealed facts of illegal hunting of wild ungulates on the territory of Irkutsk region for the period from 2008 to 2012 was taken from the materials of the reports of the State Hunting Supervision Agency of Irkutsk region on the results of promptraids for wildlife protection.

\section{Results}

The studies showed that the main factors limiting the growth in the number of reindeer (except climatic) on the territory of Irkutsk region are: high number of bears and wolves, poaching and legal hunting. The growth in the number of predators is associated primarily with the prohibition of traditional methods of the hunting for them. The high level of poaching is caused by a number of socio-economic factors and inefficient wildlife protection by the state. Purposeful selectivity of shooting following the gender and age principle is not implemented. Artificial methods do not significantly influence the formation of sexual and age structure of the population. Official data on the number of wild ungulates is inflated due to imperfection of the legislative-normative basis in the sphere of monitoring of game resources and weak state control over the census of animals. In order to increase the number of hunting animals it $s$ necessary to amend existing regulations delegating most of the Federal authority which regulate hunting in the regions. It is required to increase the funding of regional State Agency to 350 million rubles a year for protection and use of wildlife.

\section{Discussion}

The most popular methods of hunting for game animals in Irkutsk region are:

Elk: hunting, track down or drive (with dogs, without dogs, or with the use of special equipment), hunting on saline lands via ambushing, hunting on water objects using small boats, hunting during the chasing (with decoy), battue.

Red deer: hunting with dogs on the rocks, hunting on saline lands in the summer-autumn period, stalking on the feeding grounds and concentration of animals, roundup, hunting "on a roar" using the pipe (decoy);

Roe deer: roundup, stalking or ambushing on the feeding grounds, hunting during mating when they move, hunting on saline lands. Hunting "to decoy" and with dogs is practiced rarely.

Wild boar: roundup, stalking or ambushing on the feeding grounds, hunting with dogs;

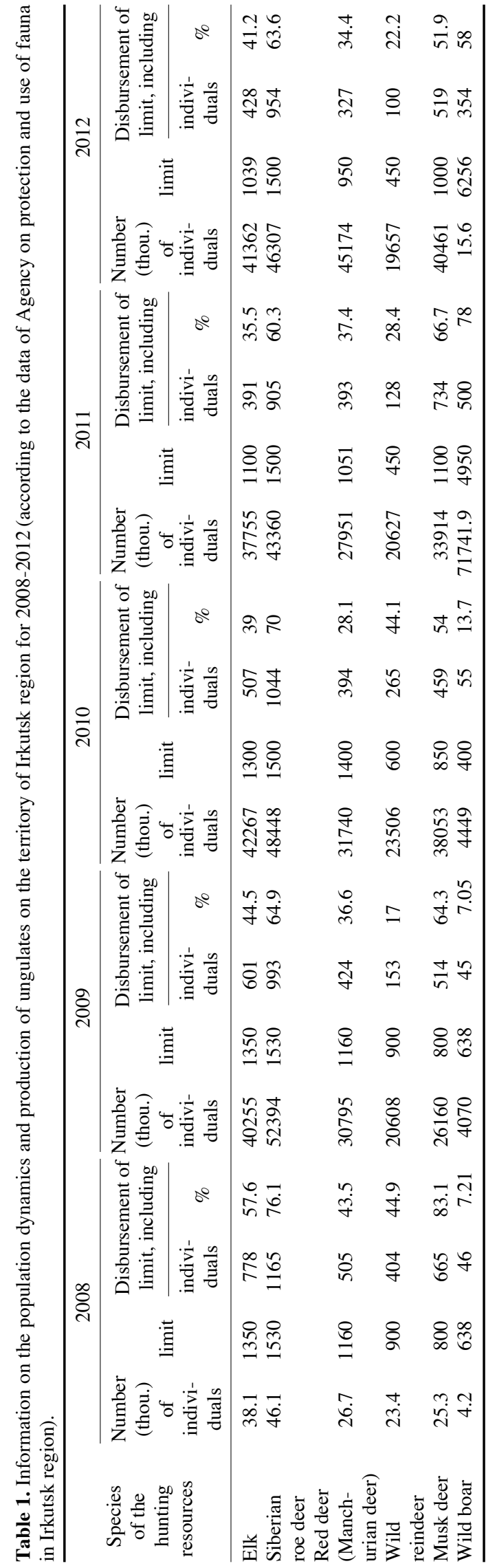


Reindeer: stalking often using snowmobiles, roundup; Musk deer: catching with loops, stalking, entice "to decoy" in summer-autumn period, hunting with dogs "on settlings", roundup.

Poachers use such illegal methods as hunting at night time with the vehicle (under the headlights), chase on the crust of ice (on the skis or using small machinery) and self traps (loops and different legs capturing and injuring devices).

Targeted selectivity of hunting for the majority of species of hunting animals is not observed. Exceptions are such specialized types of hunting as hunting for male deer during rut period to decoy (August-October) and partly hunting for males during the period of growth of horns (June-July). Particularly noteworthy is the fact that the adopted Federal rules of hunting (Hunting Rules, 2010) restricting the hunting for adult male Manchurian deer (maral) by terms from 01 to 30 September do not coincide with the period of maximum activity of deer in the Baikal region. The most intensive roar especially in the Northern regions is within the period from 15 September to 10 October. Therefore law-abiding hunters are deprived of the opportunity to hunt at the beginning of October. This increases the number of poaching in this period.

The intensity of the development of this resource is influenced primarily by economic factors, the main of which is a change in demand. Culling is practiced in a few highly organized hunting farms such as training-experimental hunting station (Goloustnoe) of the faculty of game management of Irkutsk state academy of agriculture.

Expert evaluation of the main factors (except the cli-

Table 2. The dynamics of post production number of bear and wolf on the territory of Irkutsk region for 2008-2013 (according to the data of the Agency on protection and use of fauna in Irkutsk region).

\begin{tabular}{ccccccr}
\hline \multirow{2}{*}{ Animal species } & \multicolumn{6}{c}{ Number of individuals by year (in thousands) } \\
\cline { 2 - 7 } & 2008 & 2009 & 2010 & 2011 & 2012 & 2013 \\
\hline Wolf & 2.4 & 2.54 & 3.1 & 2.8 & 2.5 & 2.1 \\
Brown bear & 10.75 & 11 & 12.2 & 12.3 & 13.1 & 12.9 \\
\hline
\end{tabular}

matic and natural mortality) affecting the number of hunting cloven-hoofed animals allows positioning them in the following order of priority:

1. Predators (primarily wolves and bears). The share of destroyed by them wild cloven-hoofed animals in the general structure of seizure is from 50 to $60 \%$.

2. Illegal (poaching) hunting. Hunting with violation of the current legislation is not less than $30 \%$ in the general structure of seizure.

3. Legal hunting provides 10 to $20 \%$ of the total production.

For this reason, the actual number of the hunting animals for different kinds is from 10 to $25 \%$ of the optimal, i.e. estimated. The data in Table 1 illustrate the dynamics of the population, limits and production of game ungulates for the last six years on the territory of Irkutsk region. The reliable positive trend in the number and, at the same time, the reduction in limits and the actual production of the elk and a red deer is observed. The most stable situation is observed with resources of the roe deer, while the number and the quota for musk deer is gradually increasing. It is assumed that the growth of the number of all species of cloven-hoofed occurs only (on paper) and is caused by subjective factors due to subjective factors, such as the desire of hunters to keep the quota volume, against the background of the reduction of Federal norms of admissible production of hunting resources. This logic implies the overstatement will be bigger number of hunting resources. This logic implies that indicators of the number of hunting resources will be overestimated. In the opinion of most experts, there are no objective reasons for such a rapid real growth of the number of the basic species of wild ungulates.

Indicators of the number of large predators such as the wolf and the brown bear are presented in Table 2 .

According to the presented data, the number of bears has been increasing steadily due to reduced hunting press on this species and the increase in the area peculiar to species of the hunting grounds but the wolf population in the past three years has been reduced. Currently, the

Table 3. Information about the revealed facts of illegal hunting of wild fauna on the territory of Irkutsk region for the period from 2008 to 2012 (according to the data of the Agency on protection and use of fauna in Irkutsk region).

\begin{tabular}{|c|c|c|c|c|c|c|c|}
\hline \multirow{2}{*}{ Parameter } & \multirow{2}{*}{ Species } & \multicolumn{5}{|c|}{ Year } & \multirow{2}{*}{ Total } \\
\hline & & 2008 & 2009 & 2010 & 2011 & 2012 & \\
\hline \multirow{6}{*}{$\begin{array}{l}\text { Registered cases of } \\
\text { illegal hunting } \\
\text { game (individuals) }\end{array}$} & Elk & \multirow{6}{*}{ No data } & \multirow{6}{*}{ No data } & 2 & - & 3 & 5 \\
\hline & Red deer & & & 3 & 1 & 1 & 5 \\
\hline & Siberian roe deer & & & 5 & 13 & 15 & 33 \\
\hline & Musk deer & & & - & 3 & 4 & 7 \\
\hline & Wild reindeer & & & - & - & - & - \\
\hline & Wild boar & & & - & - & - & - \\
\hline Total & - & $15^{*}$ & $14^{*}$ & 10 & 17 & 23 & $79 \backslash 50 * *$ \\
\hline
\end{tabular}

*In 2008-2009, the breakdown of facts of illegal hunting animals by kind of animals was not carried out. The new classification of violations was introduced from 2010; ** The total by kind of animals is calculated for 2010-2012. 
wolf population living on the territory of Irkutsk region consumes from 800 to 900 thousand tons of meat of wild ungulates per one year or 5.5-6.2\% of the entire herd. The actual ratio of the (predator-prey) is 1 to 100 , the recommended - 1 to 300 .

As mentioned above, the share of poaching in the general structure of the production of wild ungulates comprises one-third that is half times more than the legal production and makes up about 4000 thousand species of ungulates per year. Simultaneously, the data in Table 3 show that the state hunting supervision of the region reveals in average 18 cases of illegal production of animals per year, which is $0.45 \%$ of illegal production.

\section{Conclusions}

The results of the study led to the following main problems of the protection and use of populations of wild ungulates in Irkutsk region:

1. Unreliability of data of the winter route accounting of hunting resources and therefore unfounded allocated limits of production of hunting resources. This is due to:

- high financial and labor costs of hunt users on the organization of accounting work;

- the subjective approach of the organizers of the accounting work to the collection and reporting of primary data;

- weak control over the accounting work on the part of supervisors.

2. High density of large predators. With the current ratio of predators and their victims $(1 / 100)$, it is impossible to achieve the parameters of the optimal number of wild ungulates.

3 . The high level of poaching. This problem is caused both by the number of the socio-economic factors and inefficient protection of game animals. About 2 million hectares of hunting grounds fall on one state inspector in Irkutsk region.

4. Limitation of regional authorities in making decisions aimed at changing the parameters of hunting first of all its timing. Federal law (Federal law of the Russian Federation dated of July 24, 2009 N 209-FZ "About hunting and the protection of hunting resources and on amendments to certain legislative acts of the Russian Federation", 2009) does not allow local authorities to shift the terms of hunting in accordance with the changing natural conditions. This in its turn leads to growth of number of the facts of illegal hunting.

\section{REFERENCES}

Danilkin, A.A. 2006. Wild ungulates in the hunting economy (introduction to resource management) Moscow, GEOS. pp. 223-254.

Federal law of the Russian Federation dated of July 24, 2009 N 209-FZ "About hunting and the protection of hunting resources and on amendments to certain legislative acts of the Russian Federation", Collection of legislation of the Russian Federation, 27.07. 2009. No. 30, Moscow, Legal literature. pp. 140-147.

Melnikov, V.V. and V.K. Melnikov. 2008. Modern problems of organization of hunting economy of Russia, hunting tourism and analysis of its legal support it foreign countries and in Russia. M: RF Ministry of agriculture. pp. 147-152.

Report on the population dynamics and production of ungulates on the territory of Irkutsk region for 2008, Irkutsk, Agency on the protection and use of fauna of Irkutsk region, 2008. pp. 12-13.

Report on the population dynamics and production of ungulates on the territory of Irkutsk region for 2009, Irkutsk, Agency on the protection and use of fauna of Irkutsk region, 2009. pp. 10-14.

Report on the population dynamics and production of ungulates on the territory of Irkutsk region for 2010, Irkutsk, Agency on the protection and use of fauna of Irkutsk region, 2010. pp. 18-20.

Report on the population dynamics and production of ungulates on the territory of Irkutsk region for 2011, Irkutsk, Agency on the protection and use of fauna of Irkutsk region, 2011. pp. 11-15.

Report on the population dynamics and production of ungulates on the territory of Irkutsk region for 2012, Irkutsk, Agency on the protection and use of fauna of Irkutsk region, 2012. pp. 15-17.

Rules of hunting. Appendix to Order of the Ministry of natural resources and ecology of the Russian Federation from November 16, 2010 N 512, Collection of legislation of the Russian Federation, 22.11.2013. No. 47, Moscow, Legal literature, 2010. pp. 13-14.

Smirnov, M.N. 1978. General principles of artificial regulation of the ratio of genders and age composition of the populations of the Siberian Roe deer. Ways and methods of rational use and increasing the productivity of the hunting grounds, Moscow, pp. 75-77.

Smirnov, M.N. 1989. The wild ungulates in southern Siberia (historical changes of the population, problems of use). Management of populations of wild ungulates, Kirov, pp. 59-75.

Smirnov, M.N. 1990. Materials for justification of the methods of definition of rational norms, structures and terms of hunting for wild ungulates in South Siberia//Problems of game management Siberia, Krasnoyarsk, pp. 133-145.

Vinokurov, M.A. and A.R. Sukhodolov. 1998. The economy of Irkutsk region: Irkutsk: Publishing house: BGUEP, Vol. 1. pp. 6-7.

Submitted: November 27, 2013, Accepted: January 2, 2014 